\title{
Características químicas, físico-químicas e qualidade microbiológica de linguiça colonial produzida e comercializada na microrregião do município de Itapejara d'Oeste/PR
}

Maristela Dambros Sipp maridambros@yahoo.com.br
Universidade Tecnológica Federal do
Paraná, Campus Francisco Beltrão, Francisco Beltrão, Paraná, Brasil.

João Francisco Marchi Universidade Tecnológica Federal do Paraná, Campus Francisco Beltrão, Francisco Beltrão, Paraná, Brasit.

Ivane Benedetti Tonial ivane@utfpr.edu.br

Universidade Tecnológica Federal do Paraná, Campus Francisco Beltrão, Francisco Beltrão, Paraná, Brasil.

\section{RESUMO}

O consumo de embutidos cárneos tem crescido nos últimos anos, tornando-se parte da mesa de muitos consumidores brasileiros. A Linguiça Colonial é um dos produtos cárneos mais consumidos por ser facilmente encontrado e possuir preço acessível. Estes produtos são comercializados em feiras livres e supermercados e não dispõem de padronização no processo de produção refletindo em características diversificadas, e muitas vezes sem atendimento à legislação. O presente estudo teve como objetivo avaliar as características nutricionais e microbiológicas de Linguiça Colonial produzida e comercializada por agroindústrias familiares da microrregião do município de Itapejara d'Oeste/PR. Foram selecionadas cinco agroindústrias de porte familiar de embutidos cárneos para coleta das amostras e foram avaliados: a denominação apresentada no rótulo, os parâmetros físicoquímicos e microbiológicos, os quais foram comparados com a legislação para verificação da adequação quanto as normas legislativas. As linguiças rotuladas como salames coloniais não atenderam a legislação para os teores de carboidratos e nitrito residual, exceto uma delas. As linguiças rotuladas como salame tipo Italiano não atenderam a legislação quanto aos teores de umidade e nitrito residual e as linguiças denominadas Salamito não atenderam a legislação para os índices de umidade, proteína e nitrito residual. Os resultados microbiológicos (Salmonella sp, coliformes termotolerantes $45 \stackrel{\circ}{\circ} \mathrm{e}$ Staphylococcus aureus) apresentaram resultados satisfatórios e de acordo com a legislação. A diversidade dos resultados quanto aos parâmetros físico-químicos, dos quais alguns apresentam em desacordo com a legislação, sugere uma fiscalização mais intensa e uma padronização na produção de modo a garantir um alimento de qualidade.

PALAVRAS-CHAVE: Embutidos cárneos, Padrões microbiológicos, Parâmetros físicoquímicos. 


\section{INTRODUÇÃO}

O comércio dos embutidos vem apresentado significativo crescimento e alta competitividade nos últimos tempos, onde seu consumo tornou-se parte da mesa de muitos consumidores, dentre os quais se encontra a Linguiça Colonial, que é considerado um dos produtos com maior consumo devido ao processamento simples e preço acessível (CORREIA, 2008).

A Instrução Normativa (IR) no 22 de 31 de julho de 2000 do Ministério da Agricultura, Pecuária e do Abastecimento (MAPA), fixa a identidade e estabelece as características mínimas de qualidade para os diferentes tipos de salames elaborados no Brasil. Segundo o Regulamento Técnico de Identidade e Qualidade de Salame, o salame é definido como um produto cárneo industrializado obtido de carne suína ou suína e bovina, adicionado de toucinho, ingredientes, embutido em envoltórios naturais e/ou artificiais, curado, fermentado, maturado, defumado ou não e dessecado. $O$ produto pode ser denominado para venda de Salame, Salame Tipo Italiano, Salame Tipo Milano, Salame Tipo Hamburguês, Salame Tipo Friolano, Salame Tipo Calabrês, Salame Tipo Alemão, Salaminho e Linguiça Colonial, sendo caracterizado pela sua origem ou processo de produção (BRASIL, 2000).

A Linguiça Colonial, segundo o anexo XIV da IN № 22, é um produto cárneo industrializado, elaborado exclusivamente a partir de carnes suínas, adicionado de toucinho, ingredientes, moído em granulometria variável, embutida em envoltório natural. Classificado como um produto curado, que sofre um processo rápido de fermentação, defumado e embutido em envoltório natural (BRASIL, 2000).

Por ser um produto cárneo cru, e apresentar alta atividade de água, a Linguiça Colonial tem maior potencial de ocorrer desenvolvimento microorganismos podendo levar a contaminação, gerando toxinfecção (AVILA, 2011).

Este tipo de produto requer uma série de etapas na sua elaboração, o que eleva as possíveis contaminações por diversas espécies de microrganismos patogênicos ou deteriorantes, podendo comprometer a qualidade física, química e microbiológica do produto final (CORREIA, 2008).

As pequenas indústrias de produtos com registo SIM (Serviço de Inspeção Municipal), normalmente, não dispõem de laboratórios químicos capazes de monitorar a qualidade da matéria-prima e do produto acabado. Assim, eventualmente, são enviadas amostras para laboratórios prestadores de serviço que avaliam estes parâmetros. No entanto, nem sempre são apresentadas as discordâncias entre os reais valores obtidos em cada análise e o que é declarado no rótulo do produto.

Considerando o exposto, o presente estudo surgiu, para que, utilizando de métodos físico-químicos e microbiológicos oficiais se avalie as características de linguiça colonial produzidas por agroindústrias familiares da microrregião do município de Itapejara d'Oeste-PR fiscalizadas pelo serviço municipal (SIM) e pelo Serviço de Inspeção do Paraná (SIP). Almejou-se também, atestar a conformação das agroindústrias investigadas com as exigências estabelecidas pelo regulamento técnico de identidade e qualidade para linguiça colonial, as quais estão estabelecidas pela instrução normativa (IN) no 22 de 31 de julho de 2000 do ministério da agricultura, pecuária e abastecimento (MAPA), além de verificar 
a adequação às exigências microbiológicas legislada na RDC $n^{\circ} 12$ de 02 de janeiro de 2001 do ministério da saúde (BRASIL, 2001).

Neste sentido, o presente estudo objetivou avaliar as características nutricionais e microbiológicas de embutidos cárneos fermentados (Linguiça Colonial) produzidos em agroindústrias familiares da microrregião do município de Itapejara d'Oeste/PR.

\section{MATERIAIS E MÉTODOS}

\section{AMOSTRAGEM}

Foram coletadas cinco (05) amostras, em três 03 repetições totalizando quinze (15) amostras de Linguiça Colonial. Para a realização da coleta foram selecionadas cinco (05) diferentes agroindústrias da microrregião do município de Itapejara d'Oeste/PR. Para a coleta das amostras, o período de fabricação foi observado para que não houvesse grandes variações de tempo de produção. A fim de manter a privacidade das agroindústrias, as amostras foram codificadas $\mathrm{e}$ representadas pelas letras do alfabeto em maiúsculo sendo elas "A, B, C, D e E". Para o transporte as amostras foram acondicionadas em caixas térmicas e encaminhadas ao laboratório para realização das análises químicas; físicoquímicas e microbiológicas as quais foram realizadas em triplicata.

\section{ANÁLISES QUIIMICAS E FÍSICO-QUÍMICAS}

A determinação do $\mathrm{pH}$ foi realizada por método potenciométrico (AOAC, 2000) e o índice de acidez por método tritimétrico (IAL, 2008). As determinações de nitrito e nitrato foram realizadas de acordo com metodologias descritas na Instrução Normativa no 20, de 21 de julho de 1999 (LANARA, 1981). Para determinação do teor de cloreto de sódio, foi utilizado o método argentométrico de acordo com a metodologia do Ministério da Agricultura (BRASIL, 1981). A atividade de água foi determinada instrumentalmente, utilizando o aparelho AQUALAB LITE - Analisador de atividade de água- DECAGOM (BrasEq).

Os parâmetros de umidade, cinzas e proteína, lipídios forma realizados de acordo com metodologias da Association of Official Analytical Chemists (AOAC, 2000) e o teor de carboidratos totais foram obtidos por meio de cálculos, considerando a diferença entre $100 \mathrm{~g}$ da amostra e a soma do conteúdo de proteínas, gorduras, umidade e cinzas segundo o Instituto Adolfo Lutz (2008). A energia total proveniente dos nutrientes foi expressa em quilocalorias (kcal/100g), estimada a partir do somatório do percentual de proteínas e carboidratos multiplicados por quatro e o percentual de lipídios multiplicado por nove considerando a Tabela de Composição de Alimentos da Universidade de São Paulo (USP, 2015).

\section{ANÁLISES MICROBIOLÓGICAS}


realização de testes presuntivo, em caldo lauril sulfato tripsote (LST) de acordo com o MAPA (BRASIL, 2003). Staphylococcus aureus coagulase positiva empregou-se o plaqueamento em Agar Baird-Parker, com incubação a 37 ㄷ/2448 horas. Colônias foram isoladas e submetidas à coloração de Gram, catalase, coagulase, termonuclease (BRASIL, 2003). Para a pesquisa de Salmonella sp. procedeu-se a etapa de pré-enriquecimento em Água Peptonada Tamponada, com incubação a 37 ㄷ/18 horas. A seguir, na etapa de enriquecimento, empregou-se o Caldo Tetrationado Caldo Rappaport, os quais foram incubados a

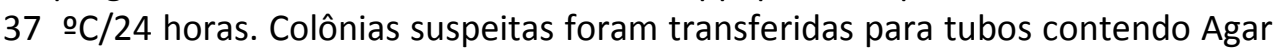
Tríplice Açúcar Ferro (TSI) e Ágar Lisina Ferro (LIA) e incubados a 37 으/24 horas (BRASIL, 2003).

\section{ANÁLISE ESTATÍ́STICA}

Os resultados químicos e físico-químicos foram submetidos ao teste de normalidade, seguido da análise de variância (ANOVA), a 5\% de probabilidade e teste de Tukey, através do software Statistica, versão 7.0 (2004).

\section{RESULTADOS E DISCUSSÃO}

A Tabela 1 apresenta a classificação dos produtos avaliados bem como o tempo de validade e sua fabricação de acordo com indicação do fabricante.

Tabela 1. Classificação dos produtos avaliados conforme especificação do produtor para venda.

\begin{tabular}{|c|c|c|c|c|}
\hline Produtores & $\begin{array}{l}\text { Tipo de Produto } \\
\text { especificado }\end{array}$ & $\begin{array}{c}\text { Fabricação do } \\
\text { produto }\end{array}$ & $\begin{array}{l}\text { Tempo de } \\
\text { validade }\end{array}$ & $\begin{array}{c}\text { Serviço de } \\
\text { Inspeção }\end{array}$ \\
\hline Amostra A & Salame Colonial & $12 / 10 / 2014$ & 45 dias & SIM \\
\hline Amostra B & Salame Colonial & 14/10/2014 & 30 dias & SIM \\
\hline Amostra C & $\begin{array}{l}\text { Salame defumado } \\
\text { tipo Italiano }\end{array}$ & 15/10/2014 & 60 dias & SIM \\
\hline Amostra D & Salamito & 10/10/2014 & 60 dias & SIP \\
\hline Amostra E & Salame Colonial & 12/10/2014 & 60 dias & SIM \\
\hline
\end{tabular}

NOTA: SIM = Serviço de Inspeção Municipal; SIP = Serviço de Inspeção Paraná.

Através da análise das informações contidas nos rótulos dos produtos cárneos fermentados avaliados, pode-se observar que existem divergências por parte dos produtores quanto à denominação exata de cada produto. De acordo com o Regulamento técnico de Identidade e Qualidade de Salames fixados pela IN n 22 (BRASIL, 2000) os tipos designados são: Salaminho, Salame tipo Alemão, Salame tipo Calabrês, Salame tipo Friolano, Salame tipo Napolitano, Salame tipo Hamburguês, Salame tipo Italiano, Salame tipo Milano. A mesma legislação 
define as características de Identidade e Qualidade para Linguiça Colonial, popularmente conhecida como Salame Colonial, embora essa terminologia não seja oficialmente correta segundo a instrução normativa 22 (BRASIL, 2000).

Apesar de existir serviços de fiscalização municipal ou estadual, nas agroindústrias selecionadas para coleta das amostras, é fato que estes órgãos não fiscalizam a denominação para venda, pois se aplicado a IN n ${ }^{\circ} 22$ (BRASIL, 2000), todas as amostras seriam classificadas como Linguiças Coloniais, pelas características físico-químicas de gordura (máxima de 30\%), Proteína (mínima de $18 \%$ ) e carboidratos totais (máximo de 1,5\%), assim como o tempo de maturação/dessecação, conforme o seu processo tecnológico empregado. A composição proximal dos embutidos cárneos fermentados avaliados no presente estudo é apresentada na Tabela 2.

Tabela 2. Composição proximal (composição físico-química) dos embutidos cárneos fermentados (linguiça colonial) produzidos e comercializados na microrregião de Itapejara d'Oeste, PR.

\begin{tabular}{cccccc}
\hline \multirow{2}{*}{ Variáveis } & A & Amostras & B & D & E \\
\cline { 2 - 6 } & Salame Colonial & Salame Colonial & $\begin{array}{c}\text { Salame defumado } \\
\text { tipo Italiano }\end{array}$ & Salamito & Salame Colonial \\
\cline { 2 - 6 } & $49,62^{\mathrm{a}} \pm 0,98$ & $58,52^{\mathrm{d}} \pm 0,98$ & $53,18^{\mathrm{b}} \pm 0,80$ & $49,07^{\mathrm{a}} \pm 0,72$ & $55,41^{\mathrm{c}} \pm 0,50$ \\
\hline Umidade (\%) & $26,86^{\mathrm{c}} \pm 0,56$ & $28,15^{\mathrm{d}} \pm 0,72$ & $26,17^{\mathrm{c}} \pm 0,15$ & $18,31^{\mathrm{a}} \pm 0,71$ & $23,44^{\mathrm{b}} \pm 0,52$ \\
PB (\%) & $15,86^{\mathrm{b}} \pm 0,92$ & $7,44^{\mathrm{a}} \pm 0,85$ & $14,44^{\mathrm{b}} \pm 0,72$ & $27,86^{\mathrm{c}} \pm 0,79$ & $15,23^{\mathrm{b}} \pm 0,92$ \\
Lipídios (\%) & $4,58^{\mathrm{a}} \pm 0,20$ & $4,69^{\mathrm{a}} \pm 0,19$ & $5,11^{\mathrm{ab}} \pm 0,13$ & $3,60^{\mathrm{c}} \pm 0,34$ & $5,38^{\mathrm{b}} \pm 0,55$ \\
Cinzas (\%) & $3,54^{\mathrm{b}} \pm 0,92$ & $0,84^{\mathrm{a}} \pm 0,74$ & $1,663^{\mathrm{ab}} \pm 0,78$ & $2,31^{\mathrm{ab}} \pm 014$ & $1,87^{\mathrm{ab}} \pm 1,18$ \\
Carboidrato(\%) & $190,52^{\mathrm{a}} \pm 1,15$ & $240,11^{\mathrm{b}} \pm 1,08$ & $271,10^{\mathrm{c}} \pm 1,45$ & $244,28^{\mathrm{b}} \pm 1,02$ & $330,57^{\mathrm{d}} \pm 1,48$ \\
\hline V.C. & & &
\end{tabular}

NOTA: PB = Proteína Bruta; V.C.= Valor Calórico (Kcal/100g). Resultados médios com as respectivas estimativas do desvio padrão. Valores na mesma linha seguidos de letras iguais não diferem entre si $(p>0,05)$ pelo teste de Tukey.

Os resultados dos parâmetros físico-químicos avaliados demonstraram que há uma ampla variação entre os nos valores encontrados. Para o teor de umidade, não diferiram significativamente $(p>0,05)$ as amostras $A$ e $D$.

As amostras identificadas como Salame Colonial (A, B e E) apresentaram teor médio de umidade que variou de $49,62 \%$ a $58,52 \%$. A Instrução Normativa (IR) $n^{\circ}$ 22 (BRASIL, 2000), não possui referência para umidade para este tipo de produto, mas baseados nas quantidades de proteína (mínimo 18\%), gordura (máximo 30\%) e carboidratos totais (máximo 1,5\%), estabelecidos por essa normativa é possível estimar que o teor de umidade seja de aproximadamente $50 \%$, cujos valores encontrados neste estudo estariam próximos.

As amostras identificadas como: Salame tipo Italiano (C) e Salamito (D) apresentaram média de $49,07 \%$ a $53,18 \%$ de umidade e segundo a IR $n^{\circ} 22$ (BRASIL, 2000) estariam fora dos padrões estabelecidos (35,00\%).

Silva et al., (2011) encontraram em quatro marcas denominadas como salames italianos coloniais teores de umidade que variaram de $54,94 \%$ a $63,44 \%$, 
sendo, estes, superiores aos encontrados no presente estudo e, de acordo com o preconizado pela legislação, os mesmos deveriam ser enquadrados e comercializados como Linguiça colonial.

Para o teor de proteínas, as amostras $A$ e $C$ não apresentaram diferença significativa $(p>0,05)$ entre si. Para os salames identificados como coloniais $(A, B$, E) os percentuais de proteínas variaram de $23,44 \%$ a $28,15 \%$ enquanto que o denominado salamito (D) apresentou média de $18,31 \%$ e o salame tipo italiano (C) média de $26,17 \%$. A IN n 22 (BRASIL, 2000) estabelece o limite mínimo para linguiça colonial de $18 \%$, e para o salame tipo italiano e o salamito o valor de $25 \%$. Considerando os valores apresentados na Tabela 2 nota-se que o percentual de proteínas para o salamito está abaixo do preconizado pela legislação. Dalla Santa (2008) avaliou a qualidade de salames artesanais e encontrou que $20 \%$ de suas amostras estavam com teor de proteína inferior ao recomendado pela legislação.

O conteúdo lipídico mostrou-se significativamente igual $(p>0,05)$ para as amostras A e C. O menor teor deste parâmetro foi encontrado na amostra B $(7,44 \%)$, e o maior para amostra D valor lipídico (27,86\%). Apesar da extrema diferença destes percentuais, essas amostras, assim como as demais, encontramse de acordo com a IN no 22 (BRASIL, 2000), na qual estabelece valor máximo de $30 \%$ de lipídios para linguiças coloniais e $32 \%$ para salames tipo italiano e Salamito.

Silva et al., (2011) encontraram diferença entre cinco marcas de salames coloniais no teor de lipídios, os valores que variaram de $6,52 \%$ a $26,7 \%$, sendo semelhantes aos encontrados neste estudo.

Para o parâmetro de minerais totais (cinzas) a amostra C (salamito) foi a que apresentou menor percentual $(3,60 \%)$ diferindo estatisticamente $(p<0,05)$ das demais. Os altos percentuais de cinzas encontrados no presente estudo podem estar relacionados com o conteúdo de cloreto de sódio adicionado a estes produtos, pois, de acordo com Dalla Santa (2008) a quantidade de sal utilizada nas formulações dos salames também pode contribuir para variação da quantidade de cinzas no produto. Barros (2011) avaliando linguiças coloniais suínas encontrou com 15 dias de fabricação $6,67 \%$ de cinzas.

Nas análises de determinação de carboidratos totais, observou-se diferença significativa $(p<0,05)$ entre as amostras $A$ e $B$. Os valores variaram de $0,84 \%$ a $3,54 \%$ para os identificados pelo produtor como Salame Colonial (A, B e E) e aqueles denominados Salame tipo Italiano (C) e Salamito (D), os valores variaram de $1,66 \%$ a 2,31\%. Conforme o Regulamento Técnico de Identidade e Qualidade para salames, o valor de carboidratos para Salame tipo Italiano e Salaminho é de máximo de $4,0 \%$, e para Linguiça Colonial estabelece máximo de 1,5\% (BRASIL, 2000). De acordo com os resultados encontrados no presente estudo, somente a amostra B, C e D apresentaram-se de acordo com a legislação.

Kunrath e Savoldi (2014) avaliaram quatro formulações de salame tipo italiano e segundo eles os carboidratos $(1,38 \%$ e $2,97 \%)$ encontravam-se de acordo com a legislação vigente (BRASIL, 2000), estando entre os valores observados neste estudo.

O valor calórico dos produtos cárneos fermentados avaliados apresentou, também, ampla variação em seus valores com o mínimo de 190,52 Kcal/100g 
(amostra A) a 330,57 Kcal/100g (amostra E). Morceli (2003) encontrou valor calórico de 309,72 Kcal/100g para salames de carne suína e bovina sem adição de cultura lática com tempo de maturação de 28 dias, estando próximo ao valor encontrado para a amostra $\mathrm{E}$.

A diversidade nos valores encontrados deve-se, possivelmente a diversificações de formulação, parâmetros de fermentação e maturação dos produtos (D'AGOSTINI; CAMPANA; DEGENHARDT, 2009).

Entre os fatores que interferem no desenvolvimento dos microrganismos estão o pH e a atividade de água (Aw), que estão relacionados com a estabilidade dos alimentos. Entretanto, no Brasil, o regulamento Técnico de Identidade e Qualidade de Salame (BRASIL, 2000), não utiliza o valor do pH como parâmetro de controle. Os parâmetros de $\mathrm{pH}$ e atividade de água (Aw), assim como outros parâmetros químicos avaliados na linguiça colonial estão apresentados na Tabela 3.

Tabela 3. Parâmetros químicos dos embutidos cárneos fermentados (linguiça colonial) produzidos e comercializados na microrregião de Itapejara d'Oeste, PR.

\begin{tabular}{cccccc}
\hline \multirow{2}{*}{ Variáveis } & \multicolumn{5}{c}{ Amostras } \\
\cline { 2 - 6 } & $\mathrm{A}$ & $\mathrm{B}$ & $\mathrm{C}$ & $\mathbf{D}$ & $\mathbf{E}$ \\
\cline { 2 - 6 } $\mathrm{pH}$ & $5,90^{\mathrm{d}} \pm 0,15$ & $4,99^{\mathrm{a}} \pm 0,07$ & $5,83^{\mathrm{c}} \pm 0,09$ & $5,29^{\mathrm{b}} \pm 0,07$ & $5,88^{\mathrm{c}} \pm 0,09$ \\
$\mathrm{Aw}$ & $0,723^{\mathrm{b}} \pm 0,02$ & $0,716^{\mathrm{ab}} \pm 0,01$ & $0,709^{\mathrm{ab}} \pm 0,01$ & $0,692^{\mathrm{a}} \pm 0,02$ & $0,711^{\mathrm{ab}} \pm 0,01$ \\
Cloretos* $^{*}$ & $2,89^{\mathrm{b}} \pm 0,11$ & $3,08^{\mathrm{b}} \pm 0,19$ & $3,50^{\mathrm{c}} \pm 0,10$ & $2,30^{\mathrm{a}} \pm 0,21$ & $3,92^{\mathrm{d}} \pm 0,35$ \\
AT $^{*}$ & $8,45^{\mathrm{a}} \pm 0,65$ & $11,61^{\mathrm{b}} \pm 0,72$ & $10,87^{\mathrm{b}} \pm 0,59$ & $8,91^{\mathrm{a}} \pm 0,85$ & $11,26^{\mathrm{b}} \pm 0,76$ \\
Nitrito** $^{*}$ & $5,91^{\mathrm{a}} \pm 0,48$ & $8,42^{\mathrm{b}} \pm 0,48$ & $6,06^{\mathrm{a}} \pm 0,43$ & $8,38^{\mathrm{b}} \pm 0,26$ & $4,71^{\mathrm{c}} \pm 0,25$ \\
Nitrato** $^{*}$ & $15,61^{\mathrm{a}} \pm 0,56$ & $21,55^{\mathrm{d}} \pm 0,94$ & $13,44^{\mathrm{c}} \pm 0,38$ & $15,52^{\mathrm{a}} \pm 0,21$ & $12,47^{\mathrm{b}} \pm 0,17$ \\
N.R. $^{* *}$ & $18,59^{\mathrm{c}} \pm 0,11$ & $25,92^{\mathrm{e}} \pm 0,95$ & $17,24^{\mathrm{b}} \pm 0,34$ & $20,99^{\mathrm{d}} \pm 0,17$ & $14,83^{\mathrm{a}} \pm 0,34$ \\
\hline \multirow{5}{*}{} & NOTA: AT $=$ Acidez Total; $*(\%) ; * *\left(\mathrm{mg} \cdot 100^{-1} \mathrm{~g}\right) ;$ N.R. Nitrito Residual. Resultados médios \\
& com as respectivas estimativas do desvio padrão. Valores na mesma linha seguidos de \\
& letras iguais não diferem entre si (p>0,05) pelo Teste de Tukey. &
\end{tabular}

Os valores de $\mathrm{pH}$ apresentaram variações de 4,99 (amostra B) a 5,90 (amostra A). A redução do pH em salames é ocasionada pela ação de bactérias lácticas sobre os açúcares com consequente produção de ácido láctico (DALLA SANTA, 2008). Embora não exista regulamento para $\mathrm{pH}$, recomenda-se que o $\mathrm{pH}$ do embutido seja reduzido para valores inferiores a 5,3 ao final do $2^{\circ}$ dia de processamento para que ocorra a inibição de micro-organismos patogênicos (ANDREOLI, 2009).

Com a produção de ácido lático, os valores da acidez total também são alterados cujos valores variaram de 8,45\% (amostra A) a 11,62\% (amostra B).

A acidez não possui uma regulamentação, no entanto, a acidez elevada assim como baixo valor de atividade de água, contribui para que embutidos cárneos fermentados sejam armazenados em temperatura ambiente, pois, os microrganismos deterioradores e patogênicos não se desenvolvem nestas condições. 
Os valores de atividade de água ( $A w)$, variaram entre as amostras avaliadas de 0,692 a 0,723. A IN $n^{\circ} 22$ (BRASIL, 2000) especifica para os produtos denominados salame tipo italiano e salamito de máximo de 0,90 para atividade de água, mas não especifica para salame colonial, no entanto, é recomendável que a atividade de água (Aw) seja inferior a 0,92. Segundo Forsyth (2000) citado por Degenhardt (2006), alguns microorganismos como a L. monocytogenes apresenta crescimento populacional ótimo com atividade de água próximo de 0,97 e mínima de 0,92 .

Os teores de cloretos variaram entre as amostras cujos valores foram de $2,30 \% 3,92 \%$. Não diferiu estatisticamente $(p>0,05)$ os valores das amostras A e $B$, todas as demais variaram estatisticamente. Degenhardt e Sant'Anna (2007), encontraram em amostras de salames coloniais produzidas no Vale do Rio do Peixe, Santa Catarina, teores de cloreto de sódio de 1,94\% a 5,57\%. Apesar de não possuir legislação para cloretos buscam-se, na atualidade, produtos que apresentem reduzido teor de sódio. Segundo Lawrence (2009) citado por Rech, (2010) a Organização Mundial de Saúde recomenda-se a ingestão de $5 \mathrm{~g}$ de sal ( $\mathrm{NaCl}$ - cloreto de sódio) por dia. Os maiores resultados encontrados para cloretos foram de 3,50\% (Amostra C) e 3,92\% (Amostra E), sendo assim, para uma pessoa não ultrapassar a dosagem de cloreto de sódio recomendada para um dia pelo consumo destes alimentos, deve ingerir no máximo $142,86 \mathrm{~g}$ do produto identificado como Amostra C e 127,55 g do produto identificado como amostra $\mathrm{E}$.

De acordo com Rech (2010) pesquisas tem revelado que o consumo de sódio por pessoas hipertensas tem contribuído para o aumento da pressão arterial, promovendo riscos de ataques cardíacos. Neste sentido, busca-se reduzir o conteúdo de sal em produtos alimentícios, no entanto, sua redução deve ser limitada uma vez que o cloreto de sódio favorece a segurança alimentar e evita efeitos indesejados na textura e flavour, assim são recomendados o mínimo de $2,25 \%$ de $\mathrm{NaCl}$.

Em relação aos teores de nitritos, os valores encontrados variaram de 4,71 a $8,42 \mathrm{mg} / 100 \mathrm{~g}$ do produto e para os níveis de nitrato, a variação observada foi de 12,45 a $21,55 \mathrm{mg} / 100 \mathrm{~g}$ do produto. $\mathrm{O}$ valor máximo de nitrato preconizado pela legislação segundo a IN $n^{\circ} 51$ de 29/12/2006 para produtos cárneos é de $0,0300 \mathrm{~g} / 100 \mathrm{~g}(30 \mathrm{mg} / 100 \mathrm{~g})$ de produto, e para nitritos é de $0,015 \mathrm{~g} / 100 \mathrm{~g}$ (15 $\mathrm{mg} / 100 \mathrm{~g}$ ) o que significa que todas as amostras avaliadas apresentam índices de nitratos e nitritos inferiores aos estabelecidos pela legislação.

Câmara et al., (2010), avaliando o teor de nitratos em linguiças comercializadas em Campo Grande, observou que uma amostra apresentou uma concentração 40 vezes acima do teor máximo permitido, e cinco vezes o valor recomendado de Ingestão Diária Aceitável (IDA). A ingestão máxima para o nitrato é de $3,7 \mathrm{mg} / \mathrm{Kg}$ de peso corporal, assim, para uma pessoa de $60 \mathrm{~kg}$ o consumo de nitrato por dia não deverá ultrapassar 0,222 g (222 mg).

Ao contrário do verificado neste estudo, Scheibler, Marchi e Souza (2013) observaram que $37,5 \%$ das amostras analisadas do Vale do Taquari apresentaram valores superiores de nitritos e nitratos residuais em relação aos limites estabelecidos pela legislação (BRASIL, 2007).

Segundo a IN $n^{\circ}$ 51/06 (BRASIL, 2007), ao ser utilizado nitrito mais nitrato, estes deverão ser convertido para nitrito residual (teor nitrato / 1,231 + teor nitrito), o valor deverá ser de no máximo $15 \mathrm{mg} / 100 \mathrm{~g}$. Os valores encontrados 
para nitrito residual variou de $14,83 \mathrm{mg} / 100 \mathrm{~g}$ (amostra E) a 25,92 mg/100g (amostra B), indicando que somente a amostra $E$ apresenta-se de acordo com o preconizado pela referida legislação.

Segundo a Organização Mundial de Saúde (OMS) estabelecido pelo Comitê FAO/OMS de Peritos em Aditivos Alimentares (JECFA) para nitrato de $0-3,7 \mathrm{mg}$ $\mathrm{Kg}^{-1}$ de peso corpóreo e para o nitrito de $0-0,07 \mathrm{mg} / \mathrm{kg}^{-1}$ de peso corporal (WHO/FAO, 2003). Sendo assim, para as duas maiores concentrações de nitrito residual encontradas $20,99 \mathrm{mg} / 100 \mathrm{~g}(0,209 \mathrm{~g} / \mathrm{kg})$ para a amostra $\mathrm{D}$ e 25,92 $\mathrm{mg} / 100 \mathrm{~g}(0,259 \mathrm{~g} / \mathrm{kg})$ para a amostra $B$, uma pessoa de $60 \mathrm{~kg}$ não deve consumir mais que 20,096 g e 16,216 gramas das linguiças $D$ e $B$, respectivamente, para não ultrapassar a ingestão diária aceitável.

O uso de nitritos e nitratos acima do limite máximo exigido pela legislação pode levar a ocorrer sérios riscos à saúde humana, possibilitando manifestações com efeitos tóxicos agudos e crônicos. A ingestão em excesso de nitritos pode levar a formação de compostos $\mathrm{N}$-nitrosos, os quais são considerados carcinogênicos, mutagênicos e teratogênicos (MELLO FILHO, BISCONTINI; ANDRADE, 2004).

$\mathrm{Na}$ Tabela 4 são apresentados os resultados obtidos para contagens de coliformes 45 oC termotolerantes, salmonela sp. e Staphylococcus aureus coagulase positiva e os limites preconizados pela legislação vigente.

Tabela 4. Resultados microbiológicos dos embutidos cárneos fermentados (linguiça colonial) produzidos e comercializados na microrregião de Itapejara d'Oeste, PR.

\begin{tabular}{lcccccc}
\multirow{2}{*}{ Análises } & Limites* & \multicolumn{5}{c}{ Resultados** } \\
\cline { 3 - 6 } & & A & B & C & D & E \\
\hline C. T & $1,0 \times 10^{3}$ & $1,0 \times 10^{2}$ & $1,0 \times 10^{1}$ & $1,0 \times 10^{1}$ & $3,5 \times 10^{1}$ & $5,6 \times 10^{1}$ \\
S.C.P & $5,0 \times 10^{3}$ & $<1,0 \times 10^{1}$ & $<1,0 \times 10^{1}$ & $<1,0 \times 10^{1}$ & $<1,0 \times 10^{1}$ & $<1,0 \times 10^{1}$ \\
Salmonella sp & Ausente & Ausente & Ausente & Ausente & Ausente & Ausente
\end{tabular}

NOTA: * Resolução RDC no 12 (2001); C.T. = Coliformes Termotolerantes 45ㅇ (UFC/g); S.C.P. = Staphylococcus aureus Coagulase Positiva (UFC/g). ${ }^{* *}$ Resultados médios das análises em triplicata.

Todas as amostras de embutido cárneos avaliadas encontram-se de acordo com a legislação e indicaram ausência de Salmonella sp. Andreoli (2009) analisando um total de 75 amostras de salames tipo italiano constatou que nenhuma apresentou Salmonella sp., diferente ao relato de Zocche, Barcellos e Bersot (2011) onde encontrou 5,9\% amostras de salames produzidas e comercializadas na região oeste do Paraná são positivas para Salmonella sp.

Para as análises de coliformes termotolerantes 45 으 e Staphylococcus aureus coagulase positiva as amostras avaliadas neste estudo também ficaram dentro do limite estabelecido pela legislação vigente (BRASIL, 2001). Embora se apresente relatado em outras pesquisas que linguiças coloniais produzidas em pequenas agroindústrias em que a fermentação vem de micro-organismos presentes da matéria-prima, sem a utilização de culturas "starter", podendo ocasionar um controle menor de micro-organismos patogênicos e/ou deterioradores (ANDREOLI, 2009). 
Andreoli (2009) contrariamente ao observado neste estudo observou que das 75 amostras analisadas de salame tipo italiano, 77,3\% ultrapassaram o limite estabelecido pela legislação para Staphylococcus aureus coagulase positiva (BRASIL, 2001). Para coliformes termotolerantes, os resultados encontrados neste estudo foram semelhantes aos resultados encontrados por Andreoli (2009) satisfazendo os limites preconizados pela legislação. Por outro lado, Dalla Santa (2008), encontraram valores de coliformes termotolerantes em salames coloniais acima dos limites da legislação.

\section{CONCLUSÃO}

Ao final do estudo pôde-se concluir que:

- Considerando os teores de umidades das amostras avaliadas, as mesmas possuem a denominação indicada nos rótulos que não condiz com o estabelecido pela legislação;

- $40 \%$ das amostras de salames coloniais apresentaram valores de carboidratos acima do limite preconizado pela legislação;

- $80 \%$ das amostras analisadas apresentaram valores de nitrito residual acima do limite estabelecido pela legislação;

- Do ponto de vista microbiológico, os resultados foram satisfatórios, atendendo as recomendações da legislação. 


\title{
Chemical, Physicochemical characteristics and microbiological quality of colonial salami produced and commercialized in the micro region of Itapejarad'Oeste - PRmunicipality
}

\begin{abstract}
The consumption of formed meat products has grown in recent years, becoming part of the meal of many Brazilian consumers. The Salami Colonial is one of the most consumed meat products to be easily found and have affordable price. These products are sold in supermarkets and free markets and lack of standardization in the production process reflecting different characteristics, and often without legal compliance. This study aimed to evaluate the nutritional and microbiological characteristics of Salami Colonial produced and marketed by family farms of the micro region of the municipality of the Itapejarad'Oeste/PR. Five agribusinesses families that produce meat products were selective for collecting the samples and were evaluated: the name displayed, chemical parameters, physicalchemical and microbiological, which were compared with the legislative norms. The salami labeled as colonial salamis did not meet the rules for contents of carbohydrates and residual nitrite, except one. The salami labeled as salami Italian type did not meet the legislation as the moisture content and residual nitrite and salami called Salamito did not meet the legislation for moisture contents, protein and residual nitrite. Microbiological results (Salmonella $s p$, fecal coliform and Staphylococcus aureus) were satisfactory and in accordance with the legislation. The diversity of results regarding the physicochemical parameters, some of which have not in accordance with the legislation, suggesting a more intense supervision and standardization in production to ensure foodquality.
\end{abstract}

KEYWORDS: Formed meat products, Microbiological standards, Physicochemical standards. 
REFERÊNCIAS

ANDREOLI, P. A. Perfil bacteriológico e determinação da atividade de água de salame tipo italano em três formas de comercialização no município de NiteróiRJ. 107 f. Dissertação (Mestrado) - Universidade Federal Fluminense, Niterói, 2009.

AVILA, A. R. A. Sensibilidade a antimicrobianos de bactérias isoladas de linguíça suína frescal: um estudo em Lavras. 114 f. Dissertação (Mestrado) - Universidade Federal de Lavras de Minas Gerais, Lavras, 2011.

AOAC - Association of Official Analytical Chemists. Official Methods of Analysis.17 ed. Washington, 2000. 1219 p.

BARROS, F. Avaliações bromatológicas e microbiológicas de linguiça colonial suína e light. 49 f. Trabalho de Conclusão de Curso - UNIVATES, Lajeado, 2011.

BRASIL. Instrução Normativa no 62 de 26 de agosto de 2003. Oficializar os métodos analíticos oficiais para análises microbiológicas para controle de produtos de origem animal e água.

BRASIL. Ministério da Agricultura. Secretaria Nacional de Defesa Agropecuária. Laboratório Nacional de Referência Animal. Queijos. In: Métodos analíticos oficiais para controle de produtos de origem animal e seus ingredientes: métodos físicos e químicos. Brasília, DF, 1981. v. II, cap. 17, p. 5.

BRASIL. Ministério da Agricultura, Pecuária e do Abastecimento. Instrução Normativa no 22 de 31 de julho de 2000. Diário Oficial da União, Brasília 03 de agosto de 2000.

BRASIL. Ministério da Agricultura e do Abastecimento. Instrução Normativa no51, 29/12/2006. Regulamento Técnico Mercosul de Atribuição de Aditivos, e seus Limites da categoria de alimentos carne e produtos cárneos. Diário Oficial da República Federativa do Brasil, Brasília, 2007. p. 14.

BRASIL. Agência Nacional de Vigilância Sanitária - ANVISA. Resolução RDC no 12, de 2 de janeiro de 2001. Regulamento técnico sobre os padrões microbiológicos para alimentos. Diário Oficial da República Federativa do Brasil, Brasília, 2001. Disponível em: http://www.anvisa.gov.br/elegis/. Acesso em: 20 fev. 2016.

CÂMARA, A. V. C; RIBAS, D. L. B; ZORZATTO, J. R. Avaliação de teores de nitrato e nitrito em linguiças, na cidade de Campo Grande, MS. Revista Higiene Alimentar, v.24, p. $175-180,2010$.

CORREIA, L. M. M. Multiplicação de microbiota autóctone e de Staphylococcus aureus inoculado em lingüiçasfrescais produzidas com diferentes concentrações de sais de cura: um estudo em Curitiba. 85 f. Dissertação (Mestrado) Universidade Federal do Paraná. Curitiba, 2008. 
DALLA SANTA, O. R. Avaliação da qualidade de salames artesanais e seleção de culturas starter para a produção de salame tipo italiano. $133 \mathrm{f}$. Tese (Doutorado) -Universidade Federal do Paraná, Curitiba, 2008.

D'AGOSTINI, F. P.; CAMPANA, P.; DEGENHARDT, R. Qualidade e identidade de Embutidos Produzidos no baixo Vale do Rio do Peixe, Santa Catarina - Brasil. Revista E-Tech: Tecnologias para Competitividade Industrial, v. 2, n. 2, 2009.

DEGENHARDT, R. SANT' ANNA, E. S. Pesquisa de listeriasp em embutidos cárneos fermentados produzidos na região meio-oeste de Santa Catarina, Brasil. Boletim do Centro de Pesquisa de Processamento de Alimentos. Curitiba, v. 25, n. 1, p. 133-140, jan./jun. 2007.

IAL - Instituto Adolfo Lutz. Métodos Químicos e Físicos para Análise de Alimentos. v.1; 3.ed.. São Paulo, 2008.

KUNRATH, C. A.; SAVOLDI, D. C. Própolis como antioxidante em produtos cárneos: aplicação e avaliação em Salame tipo italiano. 70 f.Trabalho de Conclusão de Curso - Universidade Tecnológica Federal do Paraná, Câmpus Francisco Beltrão, 2014.

LANARA (laboratório Nacional de Referência Animal). Métodos analíticos oficiais para controle de Produtos de origem animal e seus Ingredientes. Brasília: Ministério da Agricultura, Métodos Físicos e Químicos, v. 2, 1981.

MELO FILHO, A. B; BISCONTINI, T. M; ANDRADE, S. A. Níveis de nitrito e nitrato em salsichas comercializadas na região metropolitana do Recife. Ciência e Tecnologia Alimentos. v. 24, n. 3, 2004.

MORCELI, L. Utilização de bioprotetores na elaboração de embutidos fermentados. 60 f. Dissertação de Mestrado - Universidade Estadual Paulista, UNESP, Botucatu, 2003.

$\mathrm{RECH}, \mathrm{R}$. A. Produção de salame tipo italiano com teor de sódio reduzido. $69 \mathrm{f}$. Dissertação de Mestrado - Universidade Federal de Santa Maria. Santa Maria, 2010.

SCHEIBLER, J. R.; MARCHI, M. I.; SOUZA, C. F. V. Análises dos teores de nitritos e nitratos de embutidos produzidos em municípios do Vale do Taquari-RS. Revista Destaques Acadêmicos, v. 5, n. 4, 2013.

SILVA, C.; SAVARIZ, F. C.; FOLLMANN, H. M.; NUÑES, L.; CHAPLA, V. M.; SILVA, C. $F$. Análise físico-química de linguiças coloniais comercializadas no município de Toledo, Estado do Paraná. ActaScientiarum Technology, v. 33, n. 3, p. 331-336, 2011.

STATSOFT INC. Statisticadata analysis system version 7.0.Tulsa: Statsoft Inc., 2004. 
<http:/www.fcf.usp.br/tabela/>. Acesso em: 10/03/2015

WHO/FAO-WORLD Health Organization/Food Administration Organization. Food Additives Series $\mathrm{N}^{\circ}$ 50. Safety Evaluation of Certain Food Additives. Fifty-ninth Report of the Joint FAO/WHO Committee on Food Additives, Genebra, 2003.

Disponível

em:<http://www.inchem.org/documents/jecfa/jecmono/v50je05.htm>.

Acesso em: 26/05/2015.

ZOCCHE, F.; BARCELLOS, V. C.; BERSOT, L. S. Microrganismos indicadores e Salmonella $s p$. em salames produzidos e comercializados na região Oeste do Paraná. Revista Brasileira de Tecnologia Agroindustrial. v. 05, n. 01, p. 336-345, 2011.

Recebido:21 mar. 2016

Aprovado:27 set. 2016.

DOI:10.3895/rebrapa.v8n1.3839

Como citar:

SIPP, M. D; MARCHI, J. F. TONIAL, I. B.Características químicas, físico-químicas e qualidade

microbiológica de linguiça colonial produzida e comercializada na microrregião do município de Itapejata

d'Oeste - PR. Brazilian Journal of Food Research, Campo Mourão, v. 8, n.1, p. 142-155, jan./mar. 2017

Disponível em: https://periodicos.utfpr.edu.br/rebrapa

Correspondência:

Ivane Benedetti Tonial

Universidade Tecnológica Federal do Paraná, Campus Francisco Beltrão, Francisco Beltrão-PR, Brasil. Direito autoral: Este artigo está licenciado sob os termos da Licença CreativeCommons-Atribuição 4.0 Internacional.

(c) (i) 